\title{
Preparation and Characterization of Acrylic Polyurethane/Polyaniline Nanocomposite Coatings
}

\author{
Fuyou Lu ${ }^{1,2,3,4}$, Baodong Song ${ }^{1, *}$, Jixiao Wang ${ }^{1,2,3,4, *}$ \\ ${ }^{1}$ Chemical Engineering Research Center, School of Chemical Engineering and Technology, Tianjin \\ University, Tianjin 300072, PR China \\ 2 Tianjin Key Laboratory of Membrane Science and Desalination Technology, Tianjin University, \\ Tianjin 300072, PR China \\ ${ }^{3}$ State Key Laboratory of Chemical Engineering, Tianjin University, Tianjin 300072, PR China \\ ${ }^{4}$ Collaborative Innovation Center of Chemical Science and Engineering (Tianjin), Tianjin University, \\ Tianjin 300072, PR China \\ *E-mail: bdsong@tju.edu.cn, jxwang@tju.edu.cn
}

doi: $10.20964 / 2017.04 .17$

Received: 8 January 2017 / Accepted: 18 February 2017 / Published: 12 March 2017

Acrylic polyurethane and polyaniline (APU/PANI) nanocomposite coatings with excellent protective performance were prepared with physical blending method. Then, the effect of PANI nanowire on the coating's protective and mechanical properties was investigated. The protective performance of APU/PANI nanocomposite coatings was characterized by electrochemical impedance spectroscopy (EIS) technology. After immersion for 58 days in $3.5 \mathrm{wt} \% \mathrm{NaCl}$ solution at $35{ }^{\circ} \mathrm{C}$, the EIS results interestingly demonstrated that the original coating has the unexpected highest impedance value at about $1.57 \times 10^{10} \mathrm{ohms} \cdot \mathrm{cm}^{2}$ in all specimens. However, with the increase of PANI nanowire contents, the APU/PANI nanocomposite coating's impedance decreased dramatically and spot corrosion occurred gradually. That is to say, PANI nanowire has the negative effect on the protection performance of the APU nanocomposite coatings system. In addition, the results also indicated that, with increase of PANI nanowire, the APU nanocomposite coating's mechanical behavior deteriorated dramatically and water resistance decreased slightly. These experimental results will provide some helpful insights on study of PANI nanowire modified other coating systems or protective mechanism of PANI.

Keywords: polyaniline; acrylic polyurethane; coating; EIS; corrosion

\section{$\underline{\text { FULL TEXT }}$}


(C) 2017 The Authors. Published by ESG (www.electrochemsci.org). This article is an open access article distributed under the terms and conditions of the Creative Commons Attribution license (http://creativecommons.org/licenses/by/4.0/). 